\title{
VIBRATION-BASED STRUCTURAL DAMAGE DETECTION TECHNIQUES: A REVIEW
}

\author{
AKPABOT AKPABOT, ANTHONY EDE, OLUWAROTIMI OLOFINNADE, and \\ ABIMBOLA ODETOYAN
}

Dept of Civil Engineering, Covenant University, Ota, Nigeria

\begin{abstract}
Damage in infrastructure can be as a result of its degenerating state under service loads or after exposure to impact loads such as earthquakes. Early damage detection is essential to preventing failure and ensure the integrity and safety of structures. Damages lead to changes in the geometric and material properties like mass, stiffness, and damping, and influences the response behavior of the structure. It has been proven that vibration-based damage detection technique is an efficient means of damage identification and assessing structural integrity. This review article examines conventional vibration-based damage detection techniques. It highlights the importance of early damage detection as a means of ensuring infrastructural safety, reliability and maintenance. Damage detection techniques like the time domain methods, frequency domain and modal domain methods have been developed and constantly evolving to meet the existing challenge of identifying structural damages. The practical application is still minimal, hence more research works are necessary for damage detection in large civil engineering structures.
\end{abstract}

Keywords: Structural health monitoring, Structural integrity, Natural frequencies, Structural model, Response-based method, Damage identification.

\section{INTRODUCTION}

Infrastructures globally serve as a significant asset of man, and they contribute tangibly to the sustainable development of any society (Akpabot et al. 2018). Safety and reliability are the main concerns for infrastructures that are ageing or degrading (Ede et al. 2018). Damage to structure usually occurs after exposure to action forces during its service life or after the structure is subjected to impact loads or earthquakes. Structural damage leads to changes in a structural system and negatively influences current or future performances of structural components $(\mathrm{Xu}$ and Chen 2008). Damage can be said to be a divergence from original geometric or material properties of a structure due to cumulative cracks, extreme temperatures, fatigue, corrosion, or broken welds and connections leading to undesirable stresses, displacements or vibrations (Khoshnoudian and Esfandiari 2011). Due to the limitations of visual inspection, structural health monitoring (SHM) was developed to inspect and monitor the dynamic behavior of structures (Ede et al. 2004). SHM consists of understanding the functioning of the structural system under various dangerous conditions, taking precautions to reduce the possibility of damage and aiding in the remedial works of the system (Modares and Waksmanshi 2013). Many of the SHM methods in civil engineering uses modal analysis as its base because of its ability to better predict damage location (Ede et al. 2015). The vibration-based SHM system is the most preferred 
because changes in natural frequencies and modal curvatures are useful to define damage functions (Das et al. 2016).

Structural damage detection at the developing stage is imperative universally because of safety and economy concerns. The non-destructive testing (NDT) methods fundamentally are classified as local or global damage detection techniques. NDT methods like the ultrasound and acoustic emission are classified under local techniques (McCann and Forde 2001) and are used complementary to visual inspections. However, it is expected in these methods that the damaged area is known beforehand and that the concerned structure is easily accessible. Due to those demerits, local NDT methods are only useful for detection of damage on or near the surface. Vibration-based damage detection methods have, therefore evolved out of the necessity for the global identification of damage in complex structures (Kong et al. 2017). The main principle behind the vibration-based damage detection is that changes in the physical parameters (e.g., stiffness, mass, damping) will detectably affect the modal parameters (e.g., natural frequencies, modal shapes, modal damping) of the structure (Ede and Pascale 2016).

Damages are identified with connected areas, including structural health monitoring (SHM), non-destructive evaluation (NDE), and damage prognosis (Farrar and Worden 2007). SHM, as a process, focuses on global damage identification. Most times, NDE is utilized after determining the damage location to check severity and characterize damage. After identifying damage, the prognosis is necessary for the prediction of the life remaining of the structure. Depending on the kind of information available concerning the state of damage, the structural damage identification is categorized into four stages: determining occurrence of damage (stage 1), determining damage location (stage 2), damage severity quantification (stage 3), and predicting the service life remaining (stage 4) (Rytter 1993). Vibration-based methods are categorized into response-based and model-based methods (Kong et al. 2017). The response-based method interprets the dynamic structural response while in the modal parameter, changes between the original and damaged states are used for identifying damage. Based on identification stages, the response-based detection methods are capable of detecting damage in stage 1, which is usually adequate for practical purposes. Core difficulties at this stage involve selecting sensitive damage features, early-stage damage detection without raising false alarms, and elimination of environmental and operational effects (Fritzen et al. 2013). The model-based are generally used for damage identification in stage 2 and stage 3. Usually, the extent of damage and damage location are ascertained simultaneously. Stage 4 is more complex and is often connected with fracture mechanics, structural assessment, and fatigue-life analysis, which demands probabilistic failure models based on the history of component failure (Dettmann and Soeffker 2011).

\section{DETECTION OF DAMAGE OCCURRENCE}

The first stage in the damage identification process is the detection of the occurrence of damage. The response-based method is the most effective method commonly used to interpret the response data measured before and after the damage occurrence. The vibration responses are measured with sensors such as accelerometers, velocity transducer, strain gauges, displacement sensors (Kong et al. 2017). The response-based damage detection methods are classified into three groups, namely: time domain, frequency domain, and modal domain.

\subsection{Time Domain Methods}

Measurements made in the time domain contain data about the structure and eliminates errors related to the transformation to frequency domain, thereby enhancing the accuracy of the time domain approaches (Silva and Maia 1999). It requires much fewer data processing and reduces 
the risk of losing important information. Some techniques have been proposed in the time domain to determine dynamic structural properties, and they include the eigensystem realization algorithm, the least-squares complex exponential method, and the random decrement method. More recent works in the time domain are, Loh et al. (2011) who identified natural frequencies using recursive stochastic subspace identification (RSSI) and vibration signatures in the time domain was characterized by Ruocci et al. (2011). Furthermore, principal component analysis (PCA) was utilized by Nguyen et al. (2014) for damage detection, and Seyedpoor et al. (2018) proved that the Newmark time integration method and differential evolution could be useful for damage detection. These methods are useful in measuring modal parameters in the time domain.

\subsubsection{Signal processing methods}

Signal processing aims at extracting changes in vibration signals to detect, locate and quantify the damage. Signal processing methods, such as wavelet transform (WT) and Hilbert-Huang Transform (HHT), depend less on the structural shape (Kong et al. 2017). The wavelet analysis breaks down the dynamic signal of a structural response into wavelets which are a series of local basis functions (Yan and Yam 2002). The wavelet transform possesses the benefits of compression of data, computational efficiency and elimination of noise (Raich and Liszkai 2012). Due to its attendant benefits wavelet transform are widely used in biomedical, transportation and mechanical engineering fields. For instance, Quek et al. (2001) showed that the Haar wavelet is more efficient to determine the extent and location of damage in a beam. The HHT method brings out damage due to stiffness change from the measured data hence identifying the damage occurring locations (Xu and Chen 2004). Tang et al. (2011) used the HHT to detect damage due to yielding of a structural member in a five-story steel frame structure exposed to 1995, Kobe, Japan earthquake. A major limitation in the use of HHT is the mode mixing effect where waves with similar frequency are assigned to different intrinsic mode functions ( $\mathrm{Wu}$ and Huang 2009).

\subsubsection{Data-based statistical methods}

Dynamic parameters of a structure are affected by structural damage, thereby changing the statistical characteristics of measured responses. Based on a group of input-output measurements, they are used to develop an approximate mathematical model (Nigro et al. 2014). Statistical signal processing methods depend on the established statistical concepts to bring out features that change with the occurrence of damage (Nair et al. 2006). The popular models include autoregressive (AR) model and moving-average (MA) model with their various derivations. Using the AR model, Nair et al. (2006) with analytical analysis successfully detected damage in a four-story steel frame. This method removes human biases and needs a few assumptions of the physical structure. The accuracy of the model is dependent upon the approach chosen for estimating the coefficient of the model (Sanchez and Adeli 2016).

\subsection{Frequency Domain Methods}

Non-parametric and signal processing methods using Fourier transformation are used to obtain frequency response functions from time-series responses. The transformation assists in the reduction of the volume of data as well as compensating the data loss by averaging noise impacts (Ruocci 2011). Frequency response function (FRF) is the most popular, and it is the ratio of the structural response to the applied force. The technique identifies damage based on changes in stiffness, mass and other structural parameters. Liu et al. (2009) located damage in a cantilever beam using FRF shapes. Mohan et al. (2013) with the aid of particle swarm optimization assessed the use of FRF's. Errors accumulated during modal parameter extraction is eliminated 
in the measurement of FRF (Das et al. 2016). Noise interference when calculating the frequency change is a major drawback in damage detection using the FRF method. Noise level should, therefore, be kept within 5\% to ensure accurate measurements (Das et al. 2016).

\subsection{Modal Domain Methods}

The evolution of the modal analysis technique has led to the development of the modal domain methods. They are common because the modal parameters like modal shapes and natural frequencies have physical meanings. Modal methods have the advantage of being less influenced by environmental factors and supply improved results for damage location and severity (Seyedpoor et al. 2018). Using modal information for response-based damage detection is comparatively straightforward. The method supplies a huge set of sensitive damage features, for example, shifts of natural frequencies, changes in the Modal Assurance Criteria (MAC), changes in the Coordinate Modal Assurance Criteria (COMAC), and changes in the Multiple Damage Location Assurance Criterion (MDLAC). Use of higher-order derivatives of modal shapes enhances the accuracy of detection of damage in the modal domain. Xu et al. (2015) investigated the damage in plates using two-dimensional curvature mode shapes. Furthermore, studies have included methods of signal processing. Cao et al. (2012) obtained higher order derivatives using wavelet transform. A review of wavelet-based techniques for detection of damage is contained in Katunin (2015).

\section{STRUCTURAL MODELS}

After the damage is identified, the major characteristics of the structural system and damage are represented by the structural model. The structural models regularly utilized to represent the model-based identification of damage are structural matrix and finite element models. The structural matrix utilizes the damping, mass matrix or stiffness of the structural component to represent the structural system and presents the results obtained. The matrix of the structural system can be updated directly (Yang and Chen 2009) or iteratively (Friswell and Mottershead 1995). The finite element model is usually used for larger and more complex problems. The lack of a unique solution to the inverse problem is the main problem in the FE model updating process (Marwala 2010). Some available methods to handle the problem are the Bayesian approach and the regularized Lanczos method.

\section{CONCLUSIONS}

The practical application of the damage identification methods is still minimal (Moughty and Casas 2016). For full-scale structures, possible damage detection can be achieved in stages 1 and 2. Due to the challenge of scalability, damage quantification in stages 3 and 4 still poses a great challenge. Therefore, there is still a need for further research in the practical application of damage identification for full-scale structures especially as regards damage quantification and prognosis.

\section{Acknowledgments}

The authors appreciate the CUCRID for supporting the publication of this article.

\section{References}

Akpabot, A., Ede, A., Olofinnade, O., and Bamigboye, G., Predicting Buildings Collapse Due to Seismic Action in Lagos State, International Journal of Engineering Research in Africa, 37, 91-102, 2018. 
Cao, M., Cheng, L., Su, Z., and Xu, H., A Multi-Scale Pseudo Force Model in Wavelet Domain for Identification of Damage in Structural Components, Mechanical Systems and Signal Processing, 28, 638-659, April, 2012.

Das, S., Saha, P., and Patro, S. K., Vibration-Based Damage Detection Techniques Used for Health Monitoring of Structures: A Review, Journal of Civil Structural Health Monitoring, 6(3), 477-507, April, 2016.

Dettmann, K. U., and Soeffker, D., Adaptive Modeling of Reliability Properties for Control and Supervision Purposes, International Journal of Applied Mathematics and Computer Science, 21, 479486, 2011.

Ede A. N., Bonfiglioli B., Pascale G. and Viola E., Dynamic Assessment of Damage Evolution in FRPStrengthened RC Beams, Proceedings of the International Conference on Restoration, Recycling and Rejuvenation Technology for Engineering and Architectural Application, Cesena, Italy, 155-163, 2004.

Ede A. N., Ngene, B. U., and Bamigboye, G. O., Vibration-Based Structural Health Monitoring: Theoretical Foundations and Experimental Validation on Reinforced Concrete Beams, Analele Universităţii "Eftimie Murgu” Reşiţa Anul Xxii, 2, 109-120, 2015.

Ede, A., Olofinnade, O., Ofuyatan, O., Joshua, O., and Aremu, O., Use of Non-Destructive Tests to Avert the Risk of Building Collapse, International Journal of Civil Engineering and Technology (IJCIET), 9, 2028-2035, 2018.

Ede, A.N., and Pascale, G., Structural Damage Assessment of FRP Strengthened Reinforced Concrete Beams under Cyclic Loads, Materials Science Forum, 866, 139-142, 2016.

Farrar, C. R., and Worden, K., An Introduction to Structural Health Monitoring, Philosophical Transactions of Royal Society A: Mathematical, Physical and Engineering Sciences, 365, 303-315, 2007.

Friswell, M. I., and Mottershead, J. E., Finite Element Model Updating in Structural Dynamics, Kluwer Academic, Norwell, MA, USA, 1995.

Fritzen, C. P., Klinkov, M., and Kraemer, P., Vibration-Based Damage Diagnosis and Monitoring of External Loads, In Ne Trends in Structural Health Monitoring; Springer: Vienna, Germany, 149-208, 2013.

Katunin, A., Nondestructive Damage Assessment of Composite Structures Based on Wavelet Analysis of Modal Curvatures: State-of-the-Art Review and Description of Wavelet-Based Damage Assessment Benchmark, Shock and Vibration, 2015, 735219, 2015.

Khoshnoudian, F., and Esfandiari, A., Structural Damage Diagnosis Using Modal Data, Sharif Univ Technol, 18, 853-860, 2011.

Kong, X., Cai, C., and Hu, J., The State-of-the-Art on Framework of Vibration-Based Structural Damage Identification for Decision Making, Journal of Applied Sciences, 7, 497, May, 2017.

Liu, X., Lieven, N. A. J., and Escamilla-Ambrosio, P. J., Frequency Response Function Shape-Based Methods for Structural Damage Localization, Mechanical Systems and Signal Processing, 23, 12431259, 2009.

Loh, C. H., Weng, J. H., Liu, Y. C., Lin, P. Y., and Huang, S. K., Structural Damage Diagnosis Based On On-Line Recursive Stochastic Subspace Identification, Smart Mater. Struct, 20, 055004, 2011.

Marwala, T., Finite Element Model Updating Using Computational Intelligence Techniques: Applications to Structural Dynamics, Springer, Heidelberg, Germany, 2010.

McCann, D. M., and Forde, M. C., Review of NDT Methods in The Assessment of Concrete and Masonry Structures, Ndt and E International, 34, 71-84, 2001.

Modares, M., and Waksmanshi, N., Overview of Structural Health Monitoring for Steel Bridges, Am Soc Civil Eng., 18, 187-191, August, 2013.

Mohan, S. C., Maiti, D. K., and Maity, D., Structural Damage Assessment Using FRF Employing Particle Swarm Optimization, Applied Mathematics and Computation, 219, 10387-10400, 2013.

Moughty, J. J., and Casas, J. R., Vibration Based Damage Detection Techniques for Small to Medium Span Bridges: A Review and Case Study, In Proceedings of the 8th European Workshop on Structural Health Monitoring (EWSHM 2016), Bilbao, Spain, July 5-8, 2016.

Nair, K. K., Kiremidjian, A. S., and Law, K.H., Time Series-Based Damage Detection and Localization Algorithm with Application to The ASCE Benchmark Structure, J. Sound Vib., 291, 349-368, 2006.

Nguyen, V. H., Mahowald, J., Maas, S., and Golinval, J. C., Use of Time- and Frequency-Domain Approaches for Damage Detection in Civil Engineering Structures, Shock and Vibration, 872492, 2014. 
Nigro, M. B., Pakzad, S. N., and Dorvash, S., Localized Structural Damage Detection: A Change Point Analysis, Computer-Aided Civil and Infrastructure Engineering, 29(6), 416-432, 2014.

Quek, S. T., Wang, Q., Zhang, L., and Ang, K. K., Sensitivity Analysis of Notch Detection in Beams by Wavelet Technique, International Journal of Mechanical Sciences, 43, 2899-2910, December, 2001.

Raich, A. M., and Liszkai, T. R., Multi-Objective Optimization of Sensor and Excitation Layouts for Frequency Response Function-Based Structural Damage Identification, Computer-Aided Civil and Infrastructure Engineering 27(2), 95-117, 2012.

Ruocci, G., Quattrone, A., and De Stefano, A., Multi-Domain Feature Selection Aimed at The Damage Detection of Historical Bridges, Journal Physics: Conference Series, 305, 2011.

Rytter, A., Vibration-Based Inspection of Civil Engineering Structure, Department of Building Technology and Structure Engineering, Aalborg University: Aalborg, Denmark, 1993.

Sanchez, J. P., and Adeli, H., Signal Processing Techniques for Vibration-Based Health Monitoring of Smart Structures, Archives of Computational Methods in Engineering, 23, 1-15, 2016.

Seyedpoor, S.M., Ahmadi, A., and Pahnabi, N., Structural Damage Detection Using Time-Domain Responses and an Optimization Method, Inverse Problems in Science and Engineering, 27(5), 669-688, 2018.

Silva, J. M. M., and Maia, N. M. M., Modal Analysis and Testing; NATO Science Series E: Applied Sciences, Springer, Berlin, Germany, 363, 1999.

Tang, J. P., Chiou, D. J., Chen, C. W., Chiang, W. L., Hsu, W. K., Chen, C. Y., and Liu, T.Y., A Case Study of Damage Detection in Benchmark Buildings Using a Hilbert-Huang Transform-Based Method, Journal of Vibration and Control, 17(4), 623-636, 2011.

Wu, Z., and Huang, N., Ensemble Empirical Mode Decomposition: A Noise-Assisted Data Analysis Method, Advances in Adaptive Data Analysis, 1(1), 1-41, 2009.

Xu, W., Cao, M., Ostachowicz, W., Radziennski, M., and Xia, N., Two-Dimensional Curvature Mode Shape Method Based On Wavelets and Teager Energy for Damage Detection in Plates, Journal of Sound and Vibration, 347, 266-278, 2015.

Xu, Y. L., and Chen, B., Integrated Vibration Control and Health Monitoring of Building Structures Using Semi-Active Friction Dampers: Part I-Methodology, Engineering Structures, 30, 1789-1801, 2008.

$\mathrm{Xu}$, Y. L., and Chen, J., Structural Damage Detection Using Empirical Modes Decomposition: Experimental Investigation, Journal of Engineering Mechanics, 13, 1279-1288, November, 2004.

Yan, Y. J., and Yam, L. H., Online Detection of Crack Damage in Composite Plates Using Embedded Piezoelectric Actuators/Sensors and Wavelet Analysis, Composite Structures, 58, 29-38, October 2002.

Yang, Y. B., and Chen, Y. J, A New Direct Method for Updating Structural Models Based On Measured Modal Data, Engineering Structures, 31, 32-42, January, 2009. 